\title{
Molecular dynamics reveals complex compensatory effects of ionic strength on the SARS-CoV-2 Spike/hACE-2 interaction
}

Anacleto Silva de Souza ${ }^{1 \&}$, Jose David Rivera ${ }^{2 \&}$, Vitor Medeiros Almeida ${ }^{2}$, Pingju Ge ${ }^{3}$, Robson Francisco de Souza ${ }^{1}$, Chuck Shaker Farah², Henning Ulrich ${ }^{2}$, Sandro Roberto Marana $^{2}$, Roberto Kopke Salinas ${ }^{2^{*}}$, Cristiane Rodrigues Guzzo ${ }^{1^{*}}$

${ }^{1}$ Department of Microbiology, Institute of Biomedical Sciences, University of São Paulo, São Paulo, Brazil.

${ }^{2}$ Department of Biochemistry, Institute of Chemistry, University of São Paulo, São Paulo, Brazil.

${ }^{3}$ Acrobiosystems Inc., Beijing 100176, China

\& Anacleto Silva de Souza and Jose David Rivera contributed equally to this work.

* Corresponding authors

E-mail: crisguzzo@usp.br and crisguzzo@gmail.com

E-mail: roberto@iq.usp.br

\section{Running title: Effects of $\mathrm{NaCl}$ concentration on the spike-ACE-2 interface}

To whom correspondence should be addressed:

Prof. Cristiane R. Guzzo, Department of Microbiology, Institute of Biomedical Sciences, University of São Paulo, Av. Prof. Lineu Prestes, 1374, Cidade Universitária, 5508-900, São Paulo/SP, Brazil, +55 11 3091-7298; E-mail: crisguzzo@usp.br

Prof. Roberto K. Salinas, Department of Biochemistry, Institute of Chemistry, University of São Paulo, Av. Prof. Lineu Prestes, 748, Cidade Universitária, 05508-000, São PauloSP, Brazil, +55 11 3091-1475; E-mail: roberto@iq.usp.br 


\section{Abstract}

The SARS-CoV-2 pandemic has already killed more than 800,000 people worldwide. To gain entry, the virus uses its spike protein to bind to host hACE-2 receptors on the host cell surface and mediate fusion between viral and cell membranes. As initial steps leading to virus entry involves significant changes in protein conformation as well as in the electrostatic environment in the vicinity of the spike-hACE-2 complex, we explored the sensitivity of the interaction to changes in ionic strength through computational simulations and surface plasmon resonance. We identified two regions in the receptor-binding domain (RBD), E1 and E2, which interact differently with hACE-2. At high salt concentration, E2mediated interactions are weakened but are compensated by strengthening E1mediated hydrophobic interactions. These results provide a detailed molecular understanding of spike RBD/hACE-2 complex formation and stability under a wide range of ionic strengths.
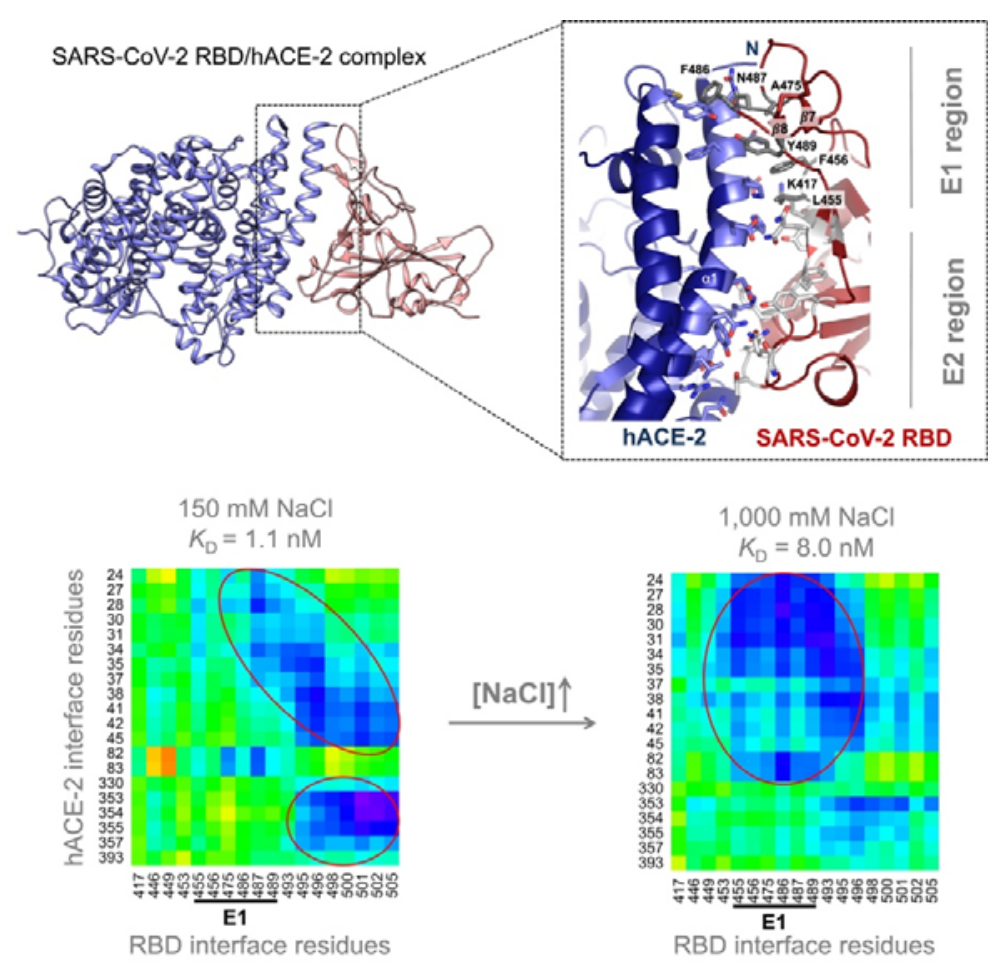

Keywords: COVID-19, pandemic, coronavirus, spike, ACE-2. 
Severe Acute Respiratory Syndrome Coronavirus 2 (SARS-CoV-2) is the etiological agent of the current outbreak of coronavirus disease (COVID-19). From late 2019 and into August 2020, SARS-CoV-2 has already infected more than 22 million and killed more than 800,000 people in 216 countries ${ }^{1}$. The cell entry mechanism is thought to be initiated by the binding of the viral Spike glycoprotein to the human angiotensin-converting enzyme (hACE-2) 2,3 expressed on the surface of airway epithelial ${ }^{4}$, kidney, intestine, macrophages and other cells ${ }^{5}$. Spike is a membrane surface trimeric protein, which contains active $\mathrm{S} 1$ and $\mathrm{S} 2$ subunits. The $\mathrm{S} 1$ subunit is involved in host cell receptorbinding and $S 2$ mediates cell and viral membrane fusion ${ }^{3,6,7}$. The hACE-2 receptor consists of $\mathrm{C}$-terminal collectrin-like and $\mathrm{N}$-terminal peptidase domains (NPD), responsible for the enzymatic activity for cleaving angiotensin II to angiotensin (1-7). The Spike S1 subunit contains a highly variable receptorbinding domain (RBD) comprising residues 331-524 (Figure S1) $3,6,7,8$. Binding of the Spike-RBD to hACE-2 NPD triggers a conformational change exposing spike S1/S2 and the S2' sites for cleavage by furin and transmembrane protease serine 2 (TMPRSS2) ${ }^{9}$, activating membrane fusion and hence virus entry ${ }^{10-13}$.

Structural studies showed that each Spike RBD interacts with one hACE-2 NPD domain through hydrogen bonding with few salt bridges and hydrophobic contacts $^{14,15}$. The spike RBD and hACE-2 complex (RBD/hACE-2) has a high binding affinity with dissociation constants $\left(K_{\mathrm{D}}\right)$ ranging from 5.1 to $44.2 \mathrm{nM}{ }^{15,16}$. During membrane fusion, Spike undergoes significant conformational changes in an environment whose electrostatic nature is also highly variable, both temporally and spatially ${ }^{17}$ and so the RBD-hACE-2 interaction must remain stable during membrane approximation, proteolytic cleavage at S2' and dissociation of the S1 and S2 subunits prior to S2-mediated membrane fusion. During this process, it is reasonable to envision significant fluctuations in the electrostatic environment in the vicinity of the RBD/hACE-2 complex. We therefore investigated how ionic strength affects complex stability using computational simulations and SPR experiments.

We characterized the molecular properties of the SARS-CoV-2 RBD/hACE-2 interface by mapping hydrophilic and hydrophobic profiles for each amino acid residue (Figure 1a and Table S1). The main differences between amino acid sequences of SARS-CoV and SARS-CoV-2 Spike proteins are located on the RBD interface with hACE-2 (Figure 1a-c). These differences alter the hydropathy profile of the RBD residues located at the interface (Figures 1c and 1d). From this analysis, we named two regions, E1 and E2 (Figure 1). The E1 region corresponds to residues 417, 455-456, 470-490. The E1 region in SARS-CoV-2 is slightly more hydrophobic than the E1 region in SARS-CoV, especially due to substitution of Tyr to Leu at position 455 and Pro to Ala at position 475, which is partly compensated by the substitution of Val to Lys at position 417 (Figures 1e; Table S1). In contrast, the E2 region, made up of residues 444-454 and 493-505 (Figure 1e), which mediates mostly polar 
interactions with hACE-2, is slightly more hydrophilic in SARS-CoV-2 (Figures 1c and e; Table S1) mainly due to substitutions Tyr to Gln at position 498 and Thr to Asn at position 501 (all SARS-CoV-2 numbering; Figure 1e; Table S1).

a)

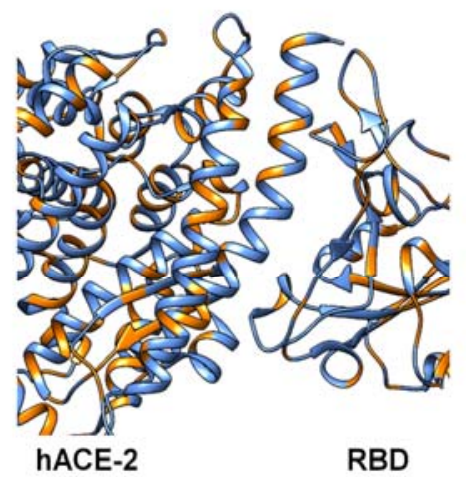

Hydrophilic residues $\square$ Hydrophobic residues b)

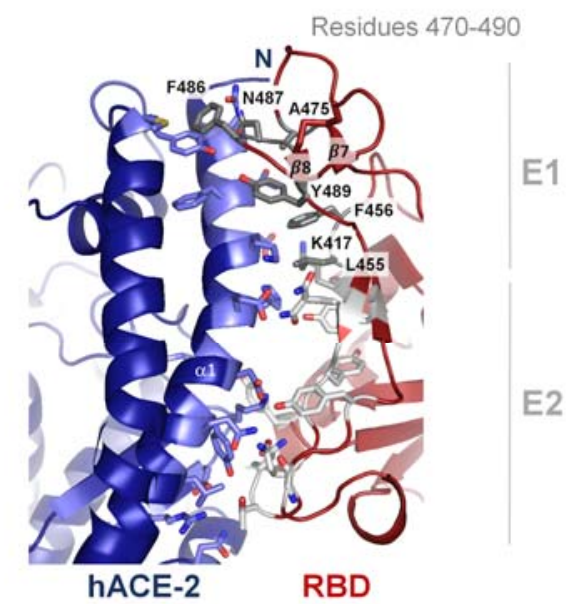

c)

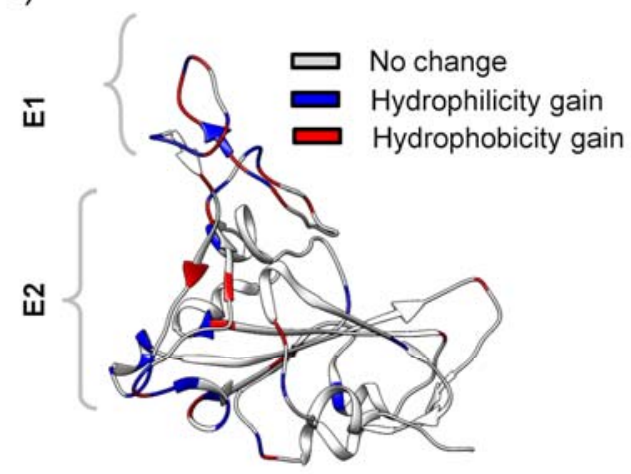

d)

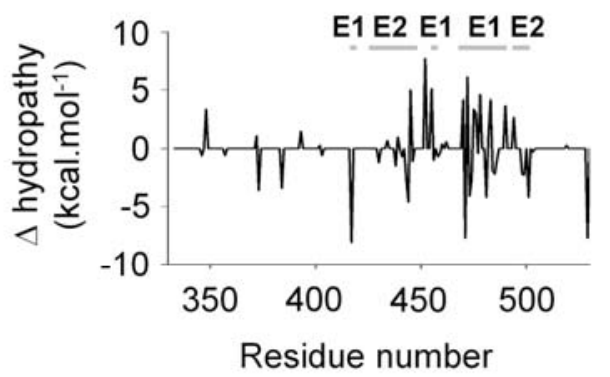

e)

SARS-COV 320 TNLCPFGEVFNATKFPSVYAWERKKISNCVADYSVLYNSTFESTFKCYGVSATKLNDLCF 379 SARS-COV 2333 TNLCPFGEVFNATREASVYAWNRKRISNCVADYSVLYNSASFSTEKCYGVSPTKLNDLCF 392

SARS-COV 380 SNVYADSFVVKGDDVRQIAPGQTGVIADYNYKLPDDFMGCVLAWNTRNIDATSTGNYNYK 439 SARS-COV 2393 TNVYADSFVIRGDEVRQIAPGQTGKIADYNYKLPDDETGCVIAWNSNNLDSKVGGNYNYL 452

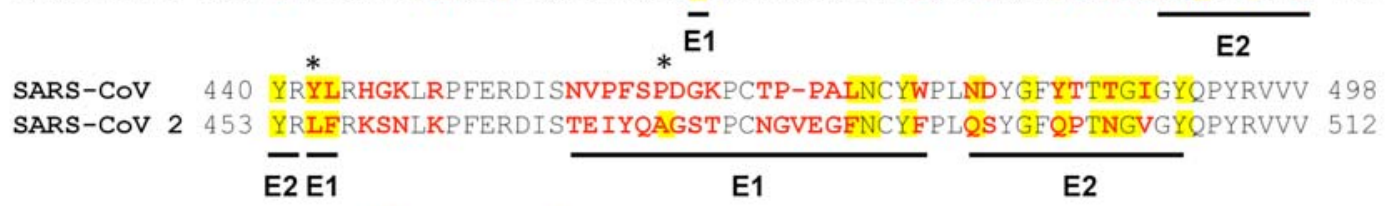

SARS-COV 499 LSEELLNAPATVCGPKLST 517 SARS-COV 2513 LSFELLHAPATVCGPKKST 531

Figure 1. Properties of SARS-CoV-2 RBD interaction interfaces. Amino acid sequence and hydropathy analysis revealed two distinct regions at the SARS-Cov-2 RBD/hACE-2 interface. Based on structural analysis and hydropathy maps, the $\mathrm{E} 1$ region was delimited by K417 and 470-490 residues and by the hydrophobic cage formed by L455 and F456. The E2 region corresponded to $446-453$ and 493-505 residues. (a) 
Hydropathy scale of SARS-CoV-2 RBD and hACE-2 color coded on the X-ray structure (PDB ID: 6MOJ) (orange: hydrophobic; blue: hydrophilic). (b) RBD/hACE-2 interface residues in the E1 and the E2 regions. (c) SARS-CoV-2 RBD/hACE-2 (PDB ID: 6M0J) crystal structure colored according to the hydropathy scale differences between SARSCoV-2 and SARS-CoV. (d) Hydropathy scale differences plotted as a function of the amino acid residue sequence. Positive values indicate a hydrophobicity gain in SARSCoV-2 relative to SARS-CoV. (e) Multiple protein sequence alignment of SARS-CoV (GenBank: AAP41037.1) and SARS-CoV-2 (GenBank: QIG55994.1) Spike RBD. Residues that undergo significant change in hydropathy are indicated with asterisk.

In order to dissect the relative contribution of the $\mathrm{E} 2$ and $\mathrm{E} 1$ regions to the stable maintenance of the SARS-CoV-2 RBD/hACE-2 complex and the potential impact of the ionic environment in the binding affinity, we first sampled the conformational space of the complex (PDB ID 6M0J) using $100 \mathrm{~ns}$ of molecular dynamics (MD) at 150, 500, and $1,000 \mathrm{mM} \mathrm{NaCl}$ concentrations (Figure 2). Analysis of the backbone root-mean-square fluctuation (RMSF) showed that the RBD residues 470-490 (in E1 region) and hACE-2 residues 129-142 (distant from the interface) experienced the largest motions (Figure 2a and $\mathbf{2 b}$ ). However, both were substantially reduced at higher ionic strengths $(1,000 \mathrm{mM} \mathrm{NaCl})$ (Figure 2a and 2b). Notably, hACE-2 sampled two major conformational states at $150 \mathrm{mM}$ $\mathrm{NaCl}$ (state 1 of RMSD of $\sim 2.4 \AA$ and state 2 of $\sim 3.4 \AA$ ) that are characterized by an opening-closing motion of residues 129-142, which is significantly affected by the salt concentration (Figure 2c and 2e, Figure S2 and S3). Interestingly, probability distributions of the backbone RMSD along the MD trajectory showed that the RBD sampled a narrower conformational ensemble at higher salt $(1,000$ $\mathrm{mM} \mathrm{NaCl}$ ) in comparison to lower salt (150 mM NaCl) (Figure 2d). Most significantly the RBD/hACE-2 complex experienced fluctuations of the interface opening angle (Figure $2 f$ and $2 \mathrm{~g}$ ). Average opening angles of $25^{\circ}, 26^{\circ}, 28^{\circ}$ were observed at 150, 500 and $1,000 \mathrm{mM} \mathrm{NaCl}$ (Figure $\mathbf{2 g}$ and Table S2), respectively, also reflected in slightly greater RBD and hACE-2 center-of-mass distances (Figure S4 and Table S3). This effect may be due to weakened polar contacts between hACE-2 and RBD at the E2 region. Indeed, interfacial hydrogen bonding analysis revealed that increased ionic strengths weakened some of the interactions between polar residue pairs in this region. Although some polar interactions in the $\mathrm{E} 1$ region are affected by increasing ionic strength such as in the case of $\mathrm{N} 487^{\mathrm{RBD}}$ that disrupts its interaction to $\mathrm{Y} 83^{\mathrm{hACE}-2}$ to perform intermolecular interactions. Some interactions are replaced to another as in the case of $\mathrm{K} 417^{\mathrm{RBD}}$ that decreases hydrogen bond (HB) occupancy to D30 ${ }^{\mathrm{hACE}-2}$ and interacts with $\mathrm{H} 34^{\mathrm{hACE}-2}$ and $\mathrm{Q} 406^{\mathrm{RBD}}$ at $1,000 \mathrm{mM} \mathrm{NaCl}$ when compared to 150 $\mathrm{mM} \mathrm{NaCl}$. Novel interactions in the $\mathrm{E} 1$ region were also observed in 1,000 $\mathrm{mM}$ $\mathrm{NaCl}$ as the case of interaction between $\mathrm{Y} 489^{\mathrm{RBD}}$ and $\mathrm{T} 27^{\mathrm{hACE}-2}$ and $\mathrm{T} 83^{\mathrm{hACE}-2}$ (Table S4). These compensatory effects together with the hydrophobic cage (L455 and F456) in the E1 region may allow the integrity of the complex in a 
broad range of salt concentrations. These observations are consistent with the nature of $\mathrm{E} 1$ and $\mathrm{E} 2$ regions.

a)

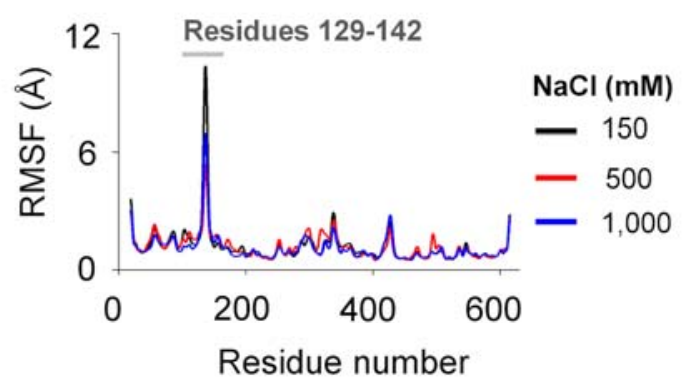

c)

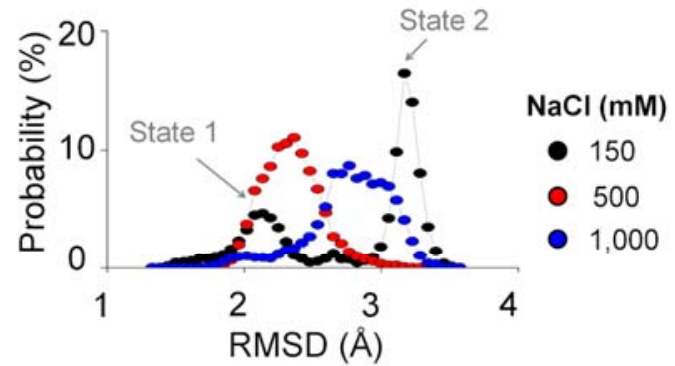

e)

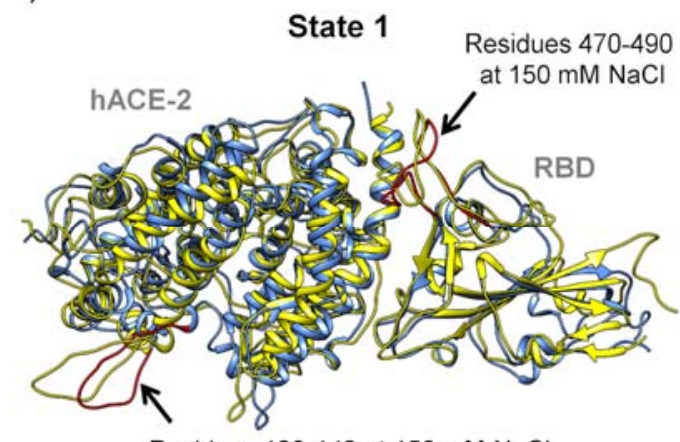

Residues $129-142$ at $150 \mathrm{mM} \mathrm{NaCl}$

f)

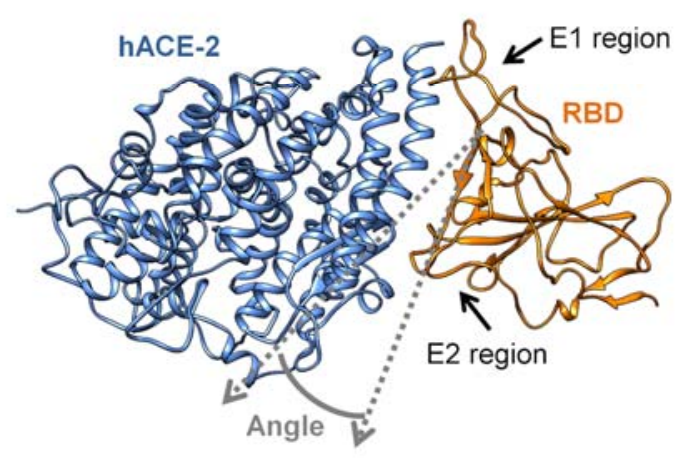

b) Spike RBD

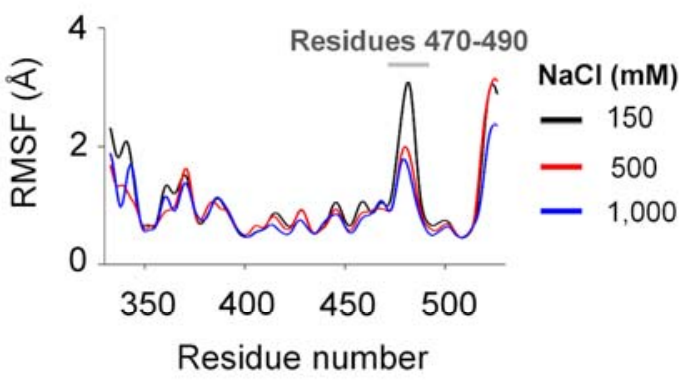

d)
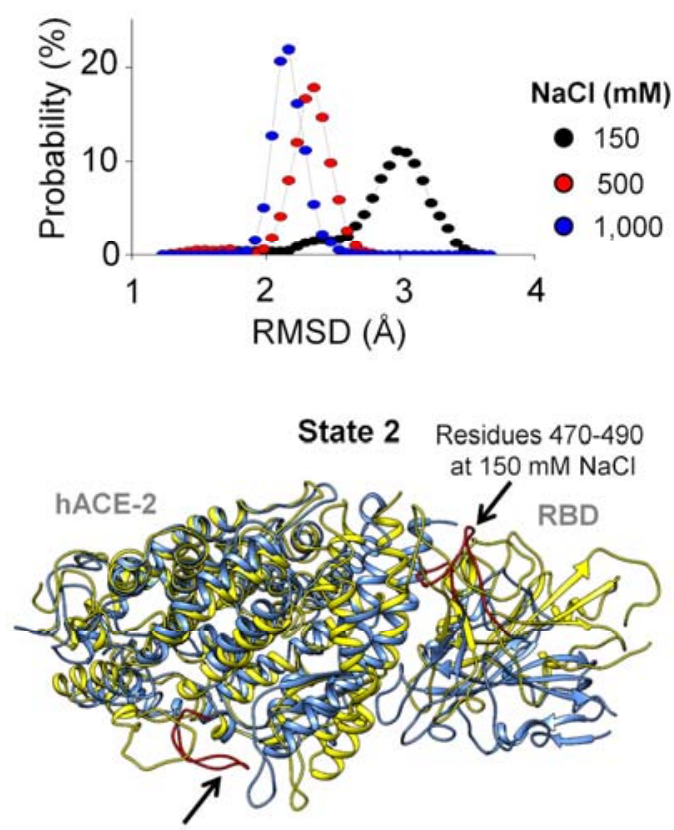

Residues $129-142$ at $150 \mathrm{mM} \mathrm{NaCl}$

g)

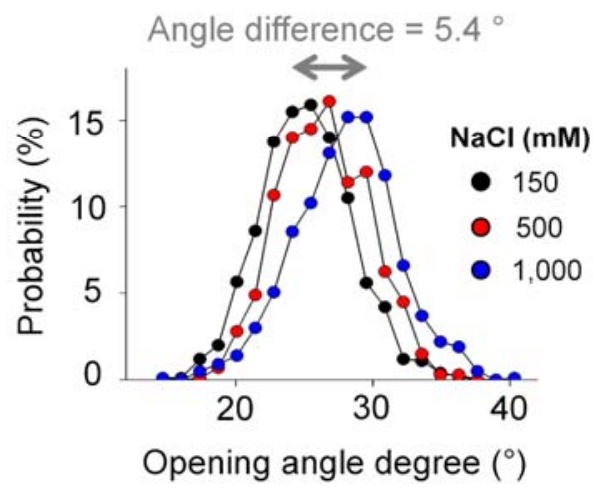

Figure 2. Structural analysis of the RBD/hACE-2 complex along the molecular dynamics simulations performed at increasing $\mathrm{NaCl}$ concentrations. Root-mean-square fluctuation (RMSF) of (a) hACE-2 and (b) RBD at different salt concentrations. (a) hACE-2 and (b) 
RBD RMSD probability distributions. (e) hACE-2 visits two conformational states in the presence of $150 \mathrm{mM} \mathrm{NaCl}$ (marked in blue) that differ mainly in the 129-142 residues (marked inthe red). The models were superimposed on a snapshot taken from the hACE-2/RBD trajectory performed at $500 \mathrm{mM} \mathrm{NaCl}$ (left; yellow) or $1,000 \mathrm{mM} \mathrm{NaCl}$ (right; yellow). RBD 470-490 residues are colored in red. (f) Opening of interaction interfaces as a function of the salt concentration. The opening is quantified based on the angle between the two vectors (gray dotted arrows) corresponding to the $\mathrm{C}_{\alpha}$ coordinates of hACE-2 $\alpha$-helix (residues 38-49) and Spike RBD $\beta$-strand (492-494 residues). (g) Probability distributions of the angles (panel f) at different salt concentrations. In all cases black refers to $150 \mathrm{mM}$, red to $500 \mathrm{mM}$, and blue to $1,000 \mathrm{mM} \mathrm{NaCl}$.

We analyzed the covariance matrix of the spatial displacements of $\mathrm{C}_{\square}$ atoms to assess internal motions of the RBD/h-ACE-2 complex (Figure S6a). This approach was based on the rationale that residues interacting through noncovalent bonds should, even afar, exert influence upon each other. A cut-off of 0.8 was adopted for the identification of significant positive and negative covariations. Covariant pairs were highly concentrated in secondary structure elements of the two proteins (Figure S6b). However, sets of covariant pairs changed at increasing $\mathrm{NaCl}$ concentrations. At $150 \mathrm{mM} \mathrm{NaCl}$, we computed 3,558 covariant residue pairs for the spike RBD/hACE-2 complex. Surprisingly, this number decreased to 2,347 at $500 \mathrm{mM} \mathrm{NaCl}$ and increased back to 3,892 at $1,000 \mathrm{mM} \mathrm{NaCl}$ (Figure 3a). Most of the covariances were intramolecular, within the RBD or hACE-2, whereas only 18, 1 and 7 intermolecular covariances were observed at 150, 500 and 1,000 mM NaCl, respectively (Figure 3b). Among them a few negative covariances ( 11 and 3 at 150 and $1000 \mathrm{NaCl}$, respectively) were present (Figure 3b). While the increase of $\mathrm{NaCl}$ concentration caused similar changes in the number of intramolecular covariances, i.e., around $30 \%$ of them were disrupted at $500 \mathrm{mM} \mathrm{NaCl}$ and recovered at $1,000 \mathrm{mM} \mathrm{NaCl}$, almost all intermolecular covariances ( 95\%) were disrupted at $500 \mathrm{mM} \mathrm{NaCl}$ and only $40 \%$ of them were re-established at $1,000 \mathrm{mM} \mathrm{NaCl}$.

Residues forming intermolecular covariant pairs were identified (Table S5). Furthermore, the seven pairs of positively correlated residues at $150 \mathrm{mM}$ $\mathrm{NaCl}$ are located in the hydrophilic E2 region at the interface of the RBD/hACE-2 complex. They were almost completely disrupted at $500 \mathrm{mM} \mathrm{NaCl}$, and four new covariant pairs were formed at the opposite side of the complex interface at 1,000 $\mathrm{mM} \mathrm{NaCl}$ solution ( $\mathrm{E} 1$ region on the $\mathrm{RBD}$ ) (Figure $3 \mathrm{c}-\mathrm{e}$ ). In order to better visualize the changes occurring as a function of the ionic strength, we also built a cross-correlation matrix of the complete set of residues, previously reported to belong to the complex interface using a cut-off of $4 \AA^{2}$ (Figure $\mathbf{3 f - h}$ ). Remarkably, $\mathrm{RBD}$ residues participating in the higher covariance pairs at $1,000 \mathrm{mM} \mathrm{NaCl}$ differed from those observed at $150 \mathrm{mM}$ (Figure 3f-h; compare red ellipses). Therefore, ionic strength increments changed the interacting regions of the complex interface, suggesting that the $\mathrm{RBD} E 1$, rather than the $\mathrm{E} 2$ region, 
becomes more firmly attached to hACE-2 at higher ionic strengths (Figure $\mathbf{3 c}-\mathbf{h}$, Table S5).

a)

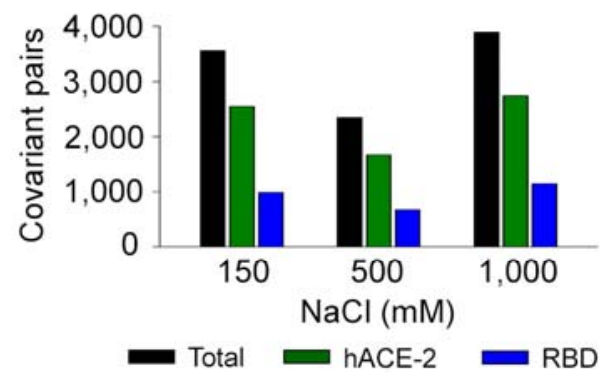

b)

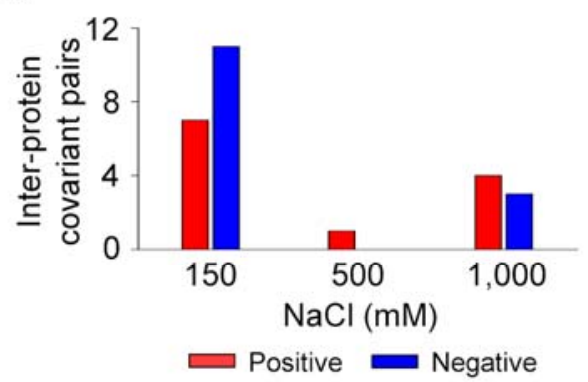

e)

c)

$150 \mathrm{mM}$

d)

$500 \mathrm{mM}$

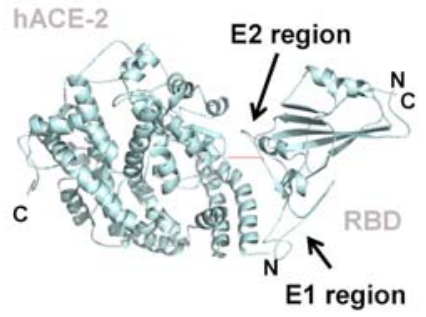

g)

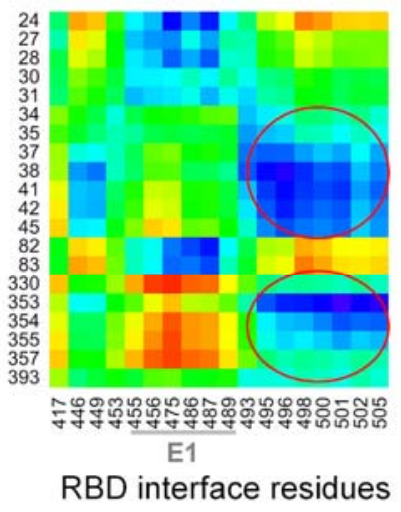

$-0.2$
$150 \mathrm{mM} \mathrm{NaCl}$

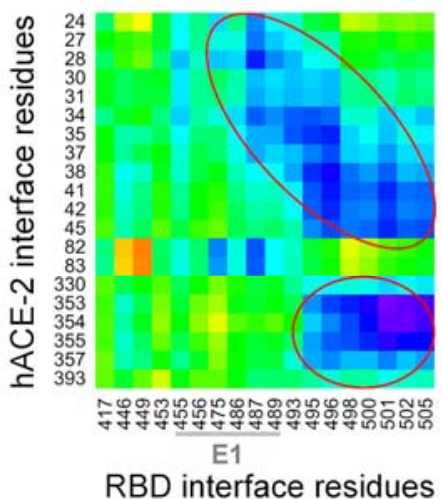

RBD interface residues
$500 \mathrm{mM} \mathrm{NaCl}$

RBD interface residues

h)
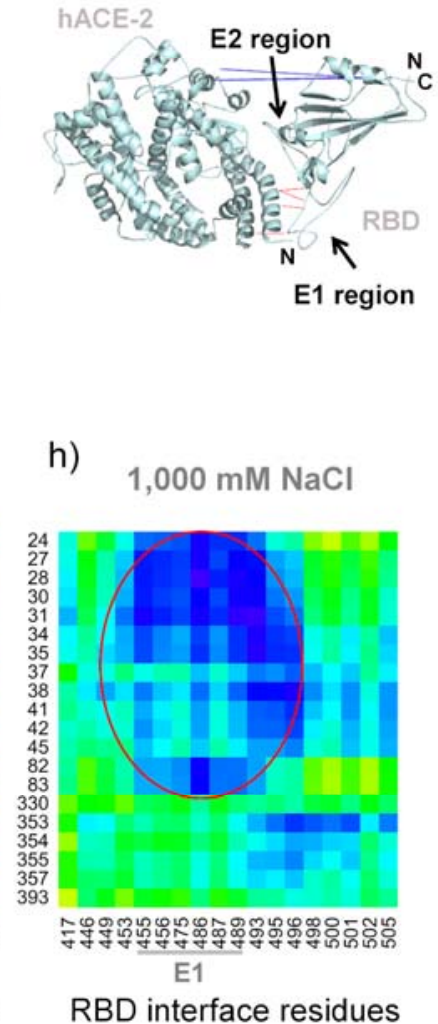

1.0
$1,000 \mathrm{mM} \mathrm{NaCl}$

Figure 3. Covariance analysis of $\mathrm{MD}$ trajectories performed at increasing $\mathrm{NaCl}$ concentrations. (a) Total of covariant pairs observed in the RBD/hACE-2 complex at different salt concentrations. (b) Residues forming intermolecular covariant pairs mapped on the RBD/hACE2 complex at (c) $150 \mathrm{mM}$, (d) $500 \mathrm{mM}$, and (e) $1,000 \mathrm{mM} \mathrm{NaCl}$. Residue pairs exhibiting positive covariance are connected by red lines, whereas negative covariant pairs are marked in blue. Displacement correlation matrix at the $\mathrm{RBD} / \mathrm{hACE}-2$ interface, with regions displaying positive covariances indicated by red 
ellipses: (f) $150 \mathrm{mM}$, (g) $500 \mathrm{mM}$, and (h) $1,000 \mathrm{mM} \mathrm{NaCl}$. Pairs of $\mathrm{C}_{\alpha}$ exhibiting covariance higher than 0.8 (positive and negative) were analyzed.

We then investigated the relative contributions of the $\mathrm{E} 1$ and $\mathrm{E} 2$ regions to complex stability in silico by applying a harmonic force with constant velocity along the dissociation pathway (Figure S5a, supplementary movies). The complex (PDB ID 6M0J) was initially relaxed for 100 ns of $\mathrm{MD}$ in each $\mathrm{NaCl}$ concentration, and a pulling force was then applied on the RBD center-of-mass while the positions of the hACE-2 atoms were restricted. Along the dissociation trajectory, the intermolecular $\mathrm{S} 19^{\mathrm{hACE}-2} / \mathrm{G} 476^{\mathrm{RBD}}$ distance remained invariant for $\sim 0.5$ and 0.8 ns at 150 and $1,000 \mathrm{mM} \mathrm{NaCl}$, respectively (Figure S5b, supplementary movies), suggesting that the intermolecular interaction at the $\mathrm{E} 1$ region became stronger at $1,000 \mathrm{mM} \mathrm{NaCl}$. This effect may result from hydrophobic interactions. In the presence of $500 \mathrm{mM} \mathrm{NaCl}$, the initial distance was around $\sim 13 \AA$ and was maintained for $0.4 \mathrm{~ns}$, in contrast to the initial distance of $5-6 \AA$ at 150 and $1,000 \mathrm{mM} \mathrm{NaCl}$. The pulling force experiment indicated the presence of weaker intermolecular interactions at $500 \mathrm{mM} \mathrm{NaCl}$ compared to further $\mathrm{NaCl}$ concentrations, since the dissociation occurred earlier in the simulation at this ionic strength. This is consistent with the absence of intermolecular covariances at $500 \mathrm{mM} \mathrm{NaCl}$. However, the $\mathrm{T} 52^{\mathrm{hACE}-2} / \mathrm{G} 502^{\mathrm{RBD}}$ distance at the $\mathrm{E} 2$ region remained invariant for $\sim 0.5 \mathrm{~ns}$ at all salt concentrations (Figure S5c, supplementary movies).

To further characterize the roles of $\mathrm{E} 2$ and $\mathrm{E} 1$ regions in RBD/hACE-2 complex stability at the different salt concentration, we simulated RBD/hACE-2 reassociation beginning with the centers of masses of the two proteins separated by $\sim 60 \AA$ (Figure 4a-c). We observed that RBD readily associates with hACE-2 after $\sim 2 \mathrm{~ns}$ and $\sim 5 \mathrm{~ns}$ at 150 and $1,000 \mathrm{mM} \mathrm{NaCl}$, respectively (Figures $4 \mathbf{b}$ and 4c), restoring the native interface (Figure S7). We noted that the RBD/hACE-2 center-of-mass separation at $1,000 \mathrm{mM}$ is slightly greater than at $150 \mathrm{mM} \mathrm{NaCl}$, as observed in the previous MD trajectory (Figure S4 and Table S3). However, association was not observed at $500 \mathrm{mM} \mathrm{NaCl}$ when initiated at $\sim 60 \AA$ separation and could only be observed when beginning the simulation at $\sim 30 \AA$ (data not shown). This is consistent with the cross-correlation analysis that showed no intermolecular covariances at $500 \mathrm{mM} \mathrm{NaCl}$ (Figure 3d).

Distance profiles were fitted to an exponential equation at 150 and 1,000 $\mathrm{mM} \mathrm{NaCl}$, each representing a free diffusion kinetics (Figure $\mathbf{4 b - c}$ and Table S6). Association rates, $k$, of 1.18 and $0.47 \mathrm{~ns}^{-1}$ were obtained at 150 and 1,000 $\mathrm{mM} \mathrm{NaCl}$, respectively (Table S6). The slower association rate observed at 1,000 $\mathrm{mM} \mathrm{NaCl}$ could be due to weaker electrostatic interactions at higher salt concentration. Indeed, a greater number of $\mathrm{Na}^{+}$or $\mathrm{Cl}^{-}$ions is observed in the vicinity of the amino acids of the interface at $1,000 \mathrm{mM}$ relative to $150 \mathrm{mM} \mathrm{NaCl}$, 
particularly near charged residues mainly in hACE-2 and in the RBD E2 region (Tables S7 and S8, Figures S8).

The free binding energy $(\triangle G)$ of the RBD/hACE2 complex was calculated with Umbrella Sampling simulations. The profiles of the potential of mean force (PMF) along the reaction coordinate $(\xi)$ at 150,500 , and $1,000 \mathrm{mM} \mathrm{NaCl}$ are shown in Figure 4. Free energy was calculated from the difference between the minimum and the maximum of the potential of mean force (PMF). Calculated dissociation constants $\left(K_{\mathrm{D}}\right)$ were 0.7 and $1.0 \mathrm{nM}$ at 150 and $1,000 \mathrm{mM} \mathrm{NaCl}$, respectively (Table 1 ). However, this difference is not statistically significant. Consistent with the previous simulations, the Umbrella Sampling calculated $K_{\mathrm{D}}$ of $290 \mathrm{nM}$ for RBD/hACE-2 complex at $500 \mathrm{mM} \mathrm{NaCl}$ is significantly higher than that determined at the other $\mathrm{NaCl}$ concentrations (Table 1).

Table 1. Free energy of Gibbs $(\Delta G)$ and dissociation constant $\left(K_{\mathrm{D}}\right)$ determined from Umbrella Sampling calculations performed in each salt concentration.

\begin{tabular}{ccc}
\hline $\mathrm{NaCl}$ concentration $(\mathrm{mM})$ & $\Delta \mathrm{G}\left(\mathrm{kcal}^{\mathrm{mol}}{ }^{-1}\right)$ & $K_{\mathrm{D}}(\mathrm{nM})$ \\
\hline 150 & $13.0 \pm 0.7$ & 0.7 \\
\hline 500 & $9.3 \pm 0.8$ & 290.0 \\
\hline 1,000 & $12.8 \pm 0.7$ & 1.0 \\
\hline
\end{tabular}

a)

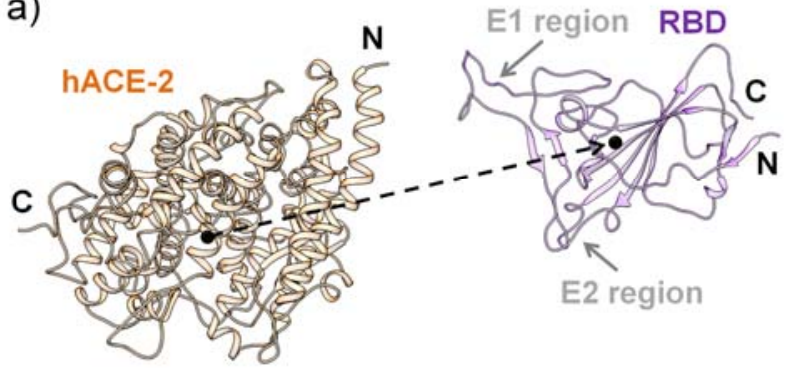

b)

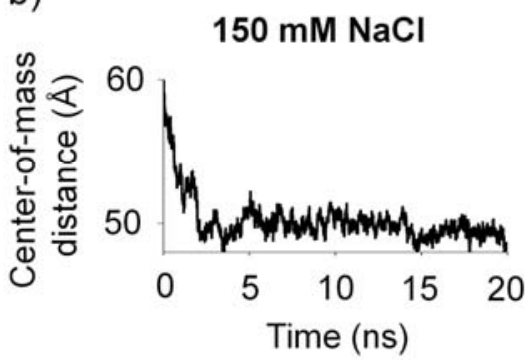

c)

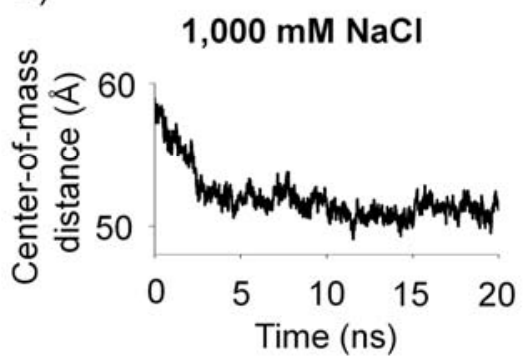

d)

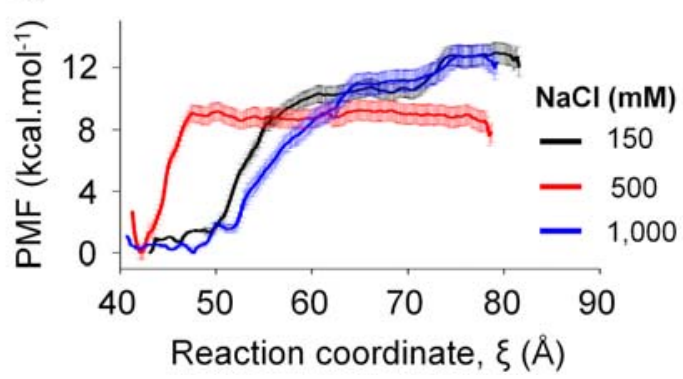

Figure 4. (a) - (c) RBD and hACE-2 reassociate after being separated by $\sim 60 \AA$ as indicated by the behavior of the center-of-mass distance as a function of the simulation time. (d) Potential of mean force (PMF) profiles obtained using the weighted histogram 
analysis method (WHAM) at different salt concentrations (150 mM, black; $500 \mathrm{mM}$, red; $1,000 \mathrm{mM}$, blue). The uncertainties were computed using 100 rounds of bootstrapping analysis. The reaction coordinate $(\xi)$ was defined as the average intermolecular vector at the interface. The structure was rotated such that the Z-axis became parallel to the reaction coordinate vector. The value of $\xi$ corresponds to the Z-component of the center-of-mass distance projected on the reaction coordinate. The energy reference level was set to the minimum corresponding to $\xi=43.1,42.2$, and $47.7 \AA$ at 150,500 , and $1,000 \mathrm{mM} \mathrm{NaCl}$, respectively.

Equilibrium $K_{D}$ were experimentally determined using surface plasmon resonance (SPR). Spike RBD/hACE-2 complex $K_{\mathrm{D}}$ were 1.1, 7.8 and 8.0 $\mathrm{nM}$ in the presence of 150,500 , and $1,000 \mathrm{mM} \mathrm{NaCl}$, respectively (Table 2, Table S9 and Figure S9), being in the same order of magnitude as the Umbrella Sampling data, particularly at 150 and $1,000 \mathrm{mM} \mathrm{NaCl}$. Furthermore, complex affinity at $1,000 \mathrm{mM} \mathrm{NaCl}$ was slightly lower than that at $150 \mathrm{mM} \mathrm{NaCl}$, which is consistent with the theoretical experiments. However, experimental $K_{\mathrm{D}}$ at $500 \mathrm{mM}$ and 1,000 $\mathrm{mM} \mathrm{NaCl}$ are nearly the same, which is in contrast to the computational experiments indicating a much lower binding affinity at this intermediate $\mathrm{NaCl}$ concentration. It is likely that intermolecular interactions become weaker at 500 $\mathrm{mM}$, compared to 150 and $1,000 \mathrm{mM} \mathrm{NaCl}$, which must be compensated by other effects, perhaps of entropic nature. However, these effects were not captured by simulations.

$K_{\mathrm{D}}$ of hACE-2 complexation with other Spike constructions were also measured experimentally (Table $\mathbf{S} 9$ and Figure S10-S12). hACE-2 binds to the trimeric Spike with $K_{\mathrm{D}}=16,8$, and $3 \mathrm{nM}$, in the presence of 150,500 , and 1,000 $\mathrm{mM} \mathrm{NaCl}$, respectively. In contrast to results obtained with RBD alone, the trimeric form Spike binds hACE-2 with higher affinity at 1,000 mM NaCl, when compared to $150 \mathrm{mM} \mathrm{NaCl}$. High ionic strength supposedly favors the up orientation of the RBD within the trimeric form Spike. The other two Spike constructs, the S1 subunit, mimicking Spike fragment release during transition from prefusion to post-fusion states and the monomeric form of the full length Spike protein, showed only marginal differences in their $K_{D}$ measured at different $\mathrm{NaCl}$ concentrations (Table 2). In all cases, association rate constants $\left(k_{\mathrm{a}}\right.$ in Table S9, and $k$ in Table S6) decrease with incrementing ionic strength, suggesting that long-range electrostatic interactions drive initial intermolecular attractions.

Table 2. Binding kinetics obtained by surface plasmon resonance experiments. Equilibrium dissociation constants $\left(K_{D}\right)$ were calculated for four spike constructs in the complex with hACE-2 in different $\mathrm{NaCl}$ concentrations.

\begin{tabular}{ccccc}
\hline $\begin{array}{c}\mathrm{NaCl} \\
(\mathbf{m M})\end{array}$ & $\begin{array}{c}\mathrm{RBD}_{319-537} / \mathrm{hACE}-2 \\
\boldsymbol{K}_{\mathrm{D}}(\mathrm{nM})\end{array}$ & $\begin{array}{c}{ }^{*} \text { Trimer }_{16-1213} / \mathrm{hACE}-2 \\
\boldsymbol{K}_{\mathrm{D}}(\mathrm{nM})\end{array}$ & $\begin{array}{c}{ }^{*} \text { Monomer }_{16-1213} / \mathrm{hACE}-2 \\
\boldsymbol{K}_{\mathrm{D}}(\mathrm{nM})\end{array}$ & $\begin{array}{c}\mathbf{S} 1_{16-685} / \mathrm{hACE}-2 \\
\boldsymbol{K}_{\mathrm{D}}(\mathrm{nM})\end{array}$ \\
\hline 50 & 4.3 & 17.4 & n.d. & n.d. \\
150 & 1.1 & 16.2 & n.d. & 12.3
\end{tabular}




\begin{tabular}{|c|c|c|c|c|}
\hline 500 & 7.8 & 8.0 & 17.8 & n.d. \\
\hline 1,000 & 8.0 & 3.3 & 15.8 & 13.3 \\
\hline
\end{tabular}

Overall, our experimental and theoretical data consistently demonstrate that a broad range of $\mathrm{NaCl}$ concentrations from 50 to $1,000 \mathrm{mM}$, does not disrupt the SARS-CoV-2 RBD/hACE-2 complex. At high ionic strengths, E2-mediated hydrophilic contacts become progressively weaker, while E1-mediated hydrophobic contacts increase to favor spike/hACE-2 complex maintenance. These features may reflect the necessity of complex stability during release of the S1 subunit that accompanies the structural transition of the Spike protein from the prefusion to the fusion intermediate state ${ }^{18}$.

\section{REFERENCE}

(1) Coronavirus https://www.who.int/emergencies/diseases/novel-coronavirus2019?gclid=EAlalQobChMI_dD0_ZX26QIVioWRCh0eHATDEAAYASAAEgKPLPD_ BwE (accessed Jun 9, 2020).

(2) Lan, J.; Ge, J.; Yu, J.; Shan, S.; Zhou, H.; Fan, S.; Zhang, Q.; Shi, X.; Wang, Q.; Zhang, L.; Wang, X. Structure of the SARS-CoV-2 Spike Receptor-Binding Domain Bound to the ACE2 Receptor. Nature 2020, 581 (7807), 215-220.

(3) Wrapp, D.; Wang, N.; Corbett, K. S.; Goldsmith, J. A.; Hsieh, C.-L.; Abiona, O.; Graham, B. S.; McLellan, J. S. Cryo-EM Structure of the 2019-nCoV Spike in the Prefusion Conformation. bioRxiv 2020. https://doi.org/10.1101/2020.02.11.944462.

(4) Leung, J. M.; Yang, C. X.; Tam, A.; Shaipanich, T.; Hackett, T.-L.; Singhera, G. K.; Dorscheid, D. R.; Sin, D. D. ACE-2 Expression in the Small Airway Epithelia of Smokers and COPD Patients: Implications for COVID-19. Eur. Respir. J. 2020, 55 (5). https://doi.org/10.1183/13993003.00688-2020.

(5) Hamming, I.; Timens, W.; Bulthuis, M. L. C.; Lely, A. T.; Navis, G. J.; van Goor, H. Tissue Distribution of ACE2 Protein, the Functional Receptor for SARS Coronavirus. A First Step in Understanding SARS Pathogenesis. J. Pathol. 2004, 203 (2), 631637.

(6) Delmas, B.; Laude, H. Assembly of Coronavirus Spike Protein into Trimers and Its Role in Epitope Expression. J. Virol. 1990, 64 (11), 5367-5375.

(7) Li, F.; Berardi, M.; Li, W.; Farzan, M.; Dormitzer, P. R.; Harrison, S. C. Conformational States of the Severe Acute Respiratory Syndrome Coronavirus Spike Protein Ectodomain. J. Virol. 2006, 80 (14), 6794-6800.

(8) Tai, W.; He, L.; Zhang, X.; Pu, J.; Voronin, D.; Jiang, S.; Zhou, Y.; Du, L. Characterization of the Receptor-Binding Domain (RBD) of 2019 Novel Coronavirus: Implication for Development of RBD Protein as a Viral Attachment Inhibitor and Vaccine. Cell. Mol. Immunol. 2020, 17 (6), 613-620.

(9) Hoffmann, M.; Kleine-Weber, H.; Pöhlmann, S. A Multibasic Cleavage Site in the Spike Protein of SARS-CoV-2 Is Essential for Infection of Human Lung Cells. Mol. Cell 2020, 78 (4), 779-784.e5.

(10) Glowacka, I.; Bertram, S.; Müller, M. A.; Allen, P.; Soilleux, E.; Pfefferle, S.; Steffen, I.; Tsegaye, T. S.; He, Y.; Gnirss, K.; Niemeyer, D.; Schneider, H.; Drosten, C.; Pöhlmann, S. Evidence That TMPRSS2 Activates the Severe Acute Respiratory 
Syndrome Coronavirus Spike Protein for Membrane Fusion and Reduces Viral Control by the Humoral Immune Response. J. Virol. 2011, 85 (9), 4122-4134.

(11) Matsuyama, S.; Nagata, N.; Shirato, K.; Kawase, M.; Takeda, M.; Taguchi, F. Efficient Activation of the Severe Acute Respiratory Syndrome Coronavirus Spike Protein by the Transmembrane Protease TMPRSS2. J. Virol. 2010, 84 (24), 1265812664.

(12) Shulla, A.; Heald-Sargent, T.; Subramanya, G.; Zhao, J.; Perlman, S.; Gallagher, T. A Transmembrane Serine Protease Is Linked to the Severe Acute Respiratory Syndrome Coronavirus Receptor and Activates Virus Entry. J. Virol. 2011, 85 (2), 873-882.

(13) Hoffmann, M.; Kleine-Weber, H.; Schroeder, S.; Krüger, N.; Herrler, T.; Erichsen, S.; Schiergens, T. S.; Herrler, G.; Wu, N.-H.; Nitsche, A.; Müller, M. A.; Drosten, C.; Pöhlmann, S. SARS-CoV-2 Cell Entry Depends on ACE2 and TMPRSS2 and Is Blocked by a Clinically Proven Protease Inhibitor. Cell 2020, 181 (2), 271-280.e8.

(14) Wang, Y.; Liu, M.; Gao, J. Enhanced Receptor Binding of SARS-CoV-2 through Networks of Hydrogen-Bonding and Hydrophobic Interactions. Proc. Natl. Acad. Sci. U. S. A. 2020, 117 (25), 13967-13974.

(15) Shang, J.; Ye, G.; Shi, K.; Wan, Y.; Luo, C.; Aihara, H.; Geng, Q.; Auerbach, A.; $\mathrm{Li}, \mathrm{F}$. Structural Basis of Receptor Recognition by SARS-CoV-2. Nature 2020, 581 (7807), 221-224.

(16) Yi, C.; Sun, X.; Ye, J.; Ding, L.; Liu, M.; Yang, Z.; Lu, X.; Zhang, Y.; Ma, L.; Gu, W.; Qu, A.; Xu, J.; Shi, Z.; Ling, Z.; Sun, B. Key Residues of the Receptor Binding Motif in the Spike Protein of SARS-CoV-2 That Interact with ACE2 and Neutralizing Antibodies. Cell. Mol. Immunol. 2020, 17 (6), 621-630.

(17) Tang, T.; Bidon, M.; Jaimes, J. A.; Whittaker, G. R.; Daniel, S. Coronavirus Membrane Fusion Mechanism Offers a Potential Target for Antiviral Development. Antiviral Res. 2020, 178, 104792.

(18) Cai, Y.; Zhang, J.; Xiao, T.; Peng, H.; Sterling, S. M.; Walsh, R. M., Jr; Rawson, S.; Rits-Volloch, S.; Chen, B. Distinct Conformational States of SARS-CoV-2 Spike Protein. Science 2020. https://doi.org/10.1126/science.abd4251. 